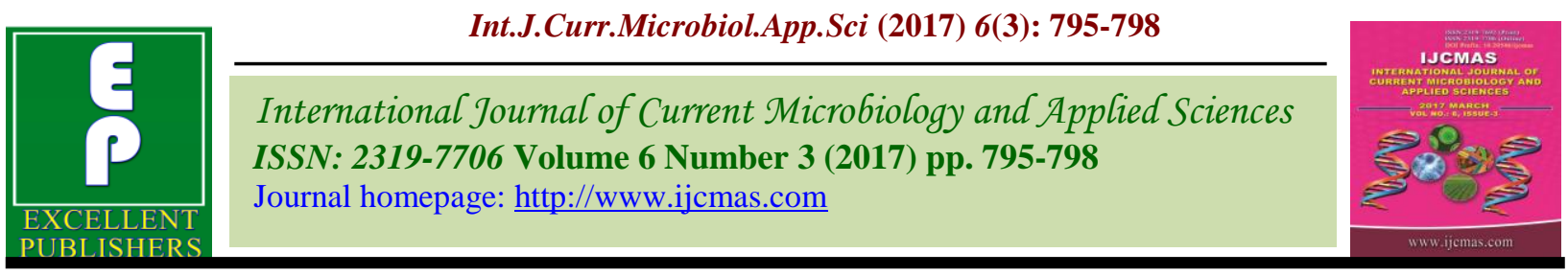

Original Research Article

https://doi.org/10.20546/ijcmas.2017.603.092

\title{
Microbiological Surveillance of Human Milk from Milk Bank in Tertiary Care Hospital in Jaipur, India
}

\author{
Neha Gupta* and Mohit Agarwal \\ Mahatma Gandhi Medical College and Hospital, Jaipur, Rajasthan 302022, India \\ *Corresponding author
}

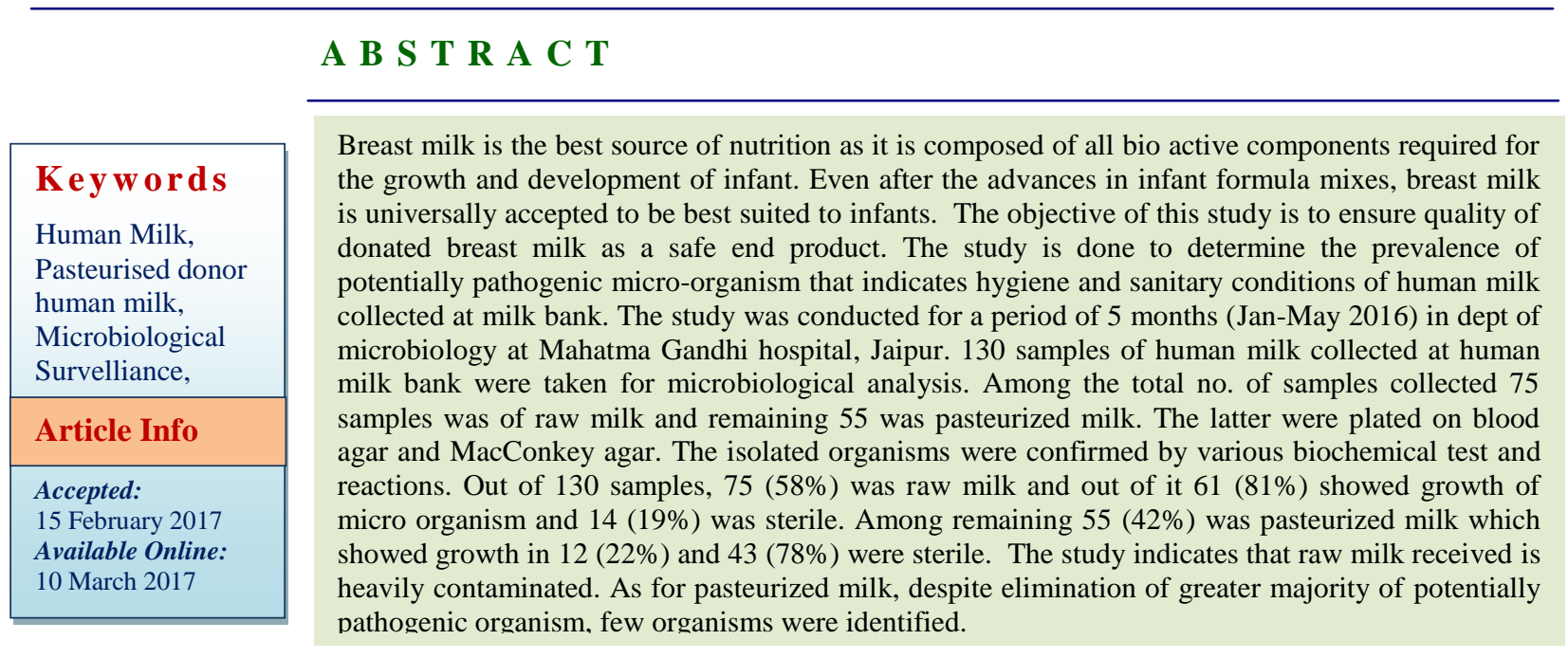

\section{Introduction}

It is universally accepted, that breast milk is the optimum exclusive source of nutrition for infants, and also continues to be the only milk which is suited to every infant around the world. Despite advances in infant formulas, human milk provides bioactive matrix of benefits that cannot be replaced by any other source of nutrition.

If mother's milk is insufficient or unavailable, the next best option is to use pasteurised donor human milk (PDHM). In our country the burden of low birth weight babies in various hospitals is about $20 \%$ with significant mortality and morbidities (Das et al., 1993; Bharti, 2011). Feeding such low birth weight babies with breast milk, can significantly reduce the risk of infections. The microbiological quality of expressed milk distributed by these milk bank is a public health issue, for the children who will consume this product, as they have low resistance to neonatal infections (Law et al., 1989; Rosa et al., 1990).

The most important issue concerning human milk bank is the bacteriological control of donated milk (Ikonam et al., 1982). Consumption of contaminated milk may be the cause of neonatal diseases (Tyson et al., 1982). The purpose of this study is to investigate the prevalence of micro-organism in expressed milk being offered by human milk bank situated in Mahatama Gandhi medical college \& hospital. 


\section{Materials and Methods}

130 samples of expressed human milk were taken from human milk bank (named Amrit Dhara), situated in Mahatma Gandhi medical college and hospital, Jaipur.

Among the total number of samples, 75 $(58 \%)$ was raw milk (unpasteurised), and remaining 55 (42\%) was pasteurised samples.

The samples were packaged immediately to microbiology laboratory in dept of microbiology at medical college, where they were submitted for microbiological analysis.

The samples were plated initially on blood agar and MacConkey agar and according to the type of micro-organism isolated, posterior identification was undergone in appropriate medium (Koneman, 1997).

Bacteria pertaining to staphylococci gender were tested for their capacity to produce coagulase and resistance to novobiocin and other biochemical tests.
In order to identify gram negative organism, screening undertaken in TSI (triple sugar iron) and other biochemical reactions and tests.

Molds and yeasts were identified by means of technique of plating on SDA (Sabourauds dextrose agar) and observing growth and morphology and microscopy (Vanderzant, 1992).

\section{Results and Discussion}

In our study, the samples collected for 5 months (Jan- may 2016) duration, undergone microbiological analysis, showed following result.

Potentially pathogenic and commensal organism were identified in $75(58 \%)$ of raw milk samples and 55 (42\%) of samples of pasteurised milk.

Percentage of positive (+ve) and negative (ve) samples found:

\begin{tabular}{|l|l|l|}
\hline MICRO-ORGANISM & $\begin{array}{l}\text { RAW } \\
\text { SAMPLES }\end{array}$ & $\begin{array}{l}\text { PASTEURISED } \\
\text { SAMPLES }\end{array}$ \\
\hline & $\mathrm{N}(\%)$ & $\mathrm{N}(\%)$ \\
\hline +ve & $61(81 \%)$ & $12(22 \%)$ \\
\hline -ve & $14(19 \%)$ & $43(78 \%)$ \\
\hline Total & $75(100 \%)$ & $55(100 \%)$ \\
\hline
\end{tabular}

Among the $61(81 \%)$ samples of raw milk with positive growth showed

$15(25 \%)$ samples presented with Staphylococcus aureus.

$26(43 \%)$ samples were S. epidermidis.

$14(23 \%)$ samples show Enterobacteriacae, with distribution of organisms as follows:

E. coli $6(43 \%)$

E. aerogenes $3(21 \%)$

K. oxytoca $5(36 \%)$
4 (6\%) samples showed growth of Pseudomonas.

2 (3\%) samples of raw milk were contaminated by molds and yeast.

Micro-organism identified in 12 (22\%) samples of pasteurised milk with growth showed:

S. aureus in $3(25 \%)$ samples

E. coli in $2(17 \%)$ samples

Pseudomonas in 2 (16\%) samples

S. epidermidis in $5(42 \%)$ samples 


\begin{tabular}{|l|l|l|}
\hline Micro-organism & Raw & Pasteurized \\
\hline S. aureus & 15 & 3 \\
\hline S. epidermidis & 26 & 5 \\
\hline E. coli & 6 & 2 \\
\hline K. oxytoca & 5 & ---- \\
\hline E. aerogens & 3 & --- \\
\hline Pseudomonas & 4 & 2 \\
\hline Candida & 2 & ---- \\
\hline
\end{tabular}

Total analysed 75and 55

+ve Samples 61 and 12

In our study the presence of high level of contaminants in raw human milk, entails in a reduction of its biological benefits, thus diminishing its protective immunological qualities. This leads to the classification of this product as improper for consumption by infants.

Furthermore, the low level of presence of micro-organism, that too, potentially non pathogenic bacteria indicate good pasteurization practice at milk bank in our hospital.

As to the raw milk, the results presented in this study are similar to those reported by others too in various study at other centers (Pereira et al., 1995; Alvaro et al., 2003).

In conclusion, human milk banks are primarily focused to provide good quality of donor milk to high risk newborns.

Therefore microbiological screening of donated and pooled milk should be done after and before pasteurization according to the protocol.

Even after pasteurization, the endotoxins of organisms are still present in the milk in some cases, but they have not been found to have any clinical effect on infant.
As per experts a bacterial count of $10^{4}$ $\mathrm{CFU} / \mathrm{ml}$ for enterobacteriacae and S.aureus are threshold values which are in consonances with milk bank operating in other parts of world (National Institute for Health and Care Excellence, 2013; Hartmann et al., 2007).

Heavily contaminated milk is discarded because pasteurisation process is not effective on such samples. No growth is acceptable in post pasteurised samples after microbiological cultures.

\section{References}

Alvaro, B., Serafini, Erica, C., Monteira. 2003. Microbiological quality of human milk from a Brazilian milk bank. Sao Paulo, vol 37 no. 6. S00 34-89.

Bhardava, K., Satish, Mishra Sudhir. 2014. For the infant and young child feeding chapter. Indian Academy of Pediatrics. J. Pediatr., vol 51: 469-73.

Bharti, P., Pal, M. 2011. Prevalance and causes of low birth weight in India. Malaysian J. Nutr., 17: 301-13

Das, B.K., Mishra, R.N., Bhargava. 1993. Comparative outcome of low birth weight babies. Indian Pediats., 30: 1521.

Hartmann, B.T., Pang, W.W., Sinner, K. 2007. Best practice guidelines for the operation of a donor human milk bank 
in Australia, NICU, 83: 667-73.

Ikonam, R.S., Groonos, P. 1982. Bacteriological quality control in human milk bank, Klin. Padiator., 194: 295-7.

Kim, J.H. \& S. Unger. 2010. Human milk bank guidelines. Canadian Pediatric Society. Nutri. Gastroenterol., Committee. Pediatric child health, 15(9): 595-598.

Koneman, E.W., Allen, S.D. 1997. Color atlas and test book of diagnostic microbiology. $5^{\text {th }}$ ed. Philadelphia: Lippincott.

Law, B., Robson, D., Romance, L. 1989. Is ingestion of milk associated bacteria by premature infants fed raw human milk controlled by routine bacteriologic screening. J. Clin. Microbiol., 27: 15066.

National Institute for Health and Care Excellence. 2013. Donor breast milk banks: donor milk bank services. NICE
Clinical guidelines, 93.

Novak, F.R. 1989. Identification de coliformes on Rev, Inst. Mat., 3: 17-9.

Pereira, et al. 1995. Presence of staphylococcus in samples of maternal milk from women with symptoms of mastitis.

Rosa, C.A., Novak, F.R., Hagler, L.C. 1990. Yeast from human milk collected in Riode Janeira, Brazil. Rev. Microbial., 21: 361-3.

Tyson, J., Rosenfeld, A., Beer, A. 1982. Collection method \& contamination of milk bank, Arch. Dis. Child, 57: 396-8.

Vanderzant, C., editors. 1992. Compendium of methods for microbiological examination of foods. $3^{\text {rd }}$ ed. Washington (DC): American Public Health Association.

Wyatt Mata, L.J. 1969. Bacteria in clostrum and milk of Guatemalan Indian women. J. Pediatr., 91: 102-7.

\section{How to cite this article:}

Neha Gupta, Mohit Agarwal. 2017. Microbiological Survelliance of Human Milk from a Milk Bank in Tertiary Care Hospital in Jaipur. Int.J.Curr.Microbiol.App.Sci. 6(3): 795-798. doi: https://doi.org/10.20546/ijcmas.2017.603.092 